\title{
Paleic acid, a fatty acid from Paenibacillus sp.: taxonomy, fermentation, isolation, structure determination, and anti-Mannheimia and -Pasteurella activity
}

\author{
Ikuko Kurata, Maya Umekita, Tsutomu Sawa, Seiko Hattori, Chigusa Hayashi, Naoko Kinoshita, \\ Yoshiko Homma, Masayuki Igarashi, Masa Hamada, Takumi Watanabe, Ryuichi Sawa, Hiroshi Naganawa, \\ Yoshikazu Takahashi and Yuzuru Akamatsu
}

Paleic acid (1), an antibiotic, was obtained from a fermentation broth of Paenibacillus sp. BMK771-AF3. The compound is a fatty acid $(9 Z, 16 R)$-16-hydroxy-9-octadecenoic acid $((R)$-16-hydroxyoleic acid), whose isolation required protection of its polar functional groups. Mosher esters of paleic acid yielded information on the absolute configuration of secondary alcohol, and well-resolved ${ }^{1} \mathrm{H}$ NMR peaks around the double bond suggested that olefin adopted a $Z$ geometry. Paleic acid showed potent antibacterial activity and narrow spectrum against Mannheimia haemolytica with MIC values ranging between 0.78 and $1.56 \mu \mathrm{g} \mathrm{ml}^{-1}$.

The Journal of Antibiotics (2010) 63, 519-523; doi:10.1038/ja.2010.90; published online 28 July 2010

Keywords: antibacterial agents; fatty acid; Mannheimia haemolytica; paleic acid; $(R)$-16-hydroxylinoleic acid; veterinary drug

\section{INTRODUCTION}

Isolates of Mannheimia haemolytica ${ }^{1}$ and Pasteurella multocida ${ }^{2}$ are representative pathogens that cause a wide range of diseases in foodproducing animals, such as cattle, poultry, pigs and rabbits. Especially, M. haemolytica is known as the primary bacterial pathogen of bovine respiratory disease, and antimicrobial agents are powerful tools for controlling infection. In fact, Tilmicosin, ${ }^{3,4}$ a derivative of desmycosin, was found to be effective against bovine respiratory disease and was introduced into the US market in 1990. Afterwards, a variety of antibiotics including $\beta$-lactams, macrolides, tetracycline and sulfonamides were shown to be effective against infectious diseases caused by these pathogens. ${ }^{5,6}$ One of the most successful veterinary drugs is a triamilide class of macrolide, tulathromycin ${ }^{7}$ (the active ingredient of Draxxin Injectable Solution launched from Pfizer Animal Health, New York, NY, USA), which has been approved for use in the treatment and prevention of bovine respiratory disease and the treatment of swine respiratory disease in the European Union and the United States of America. However, the prevalence of antimicrobial resistance among the pathogens ${ }^{8}$ requires the development of a new class of antibiotics with unique structure and/or mode of action.

Herein we describe the isolation and structural elucidation of oxygenated unsaturated C18-fatty acid 1 (paleic acid, (9Z,16R)-16- hydroxy-9-octadecenoic acid, $(R)$-16-hydroxyoleic acid), which is produced by these microorganisms and is depicted in Figure 1. Paleic acid displays antibacterial activities against a number of strains of M. haemolytica and P. multocida. This is the first report of a fatty acid derivative being effective toward these pathogens.

Moreover, $(R)$-16-hydroxylinoleic acid (2) was also isolated along with $\mathbf{1}$, albeit modest biological activity. Compounds 1 and 2 already reported as the components of products of biotransformation using oleic acid and linoleic acid as substrates. ${ }^{9,10}$ However, spectroscopic characterization and investigation on biological activity of these compounds has not been carried out.

\section{RESULTS AND DISCUSSION}

Isolation of paleic acid (1) and (R)-16-hydroxylinoleic acid (2) The fermentation broth contained $\mathbf{1}$ and $\mathbf{2}$ along with other fatty acids of high structural similarity. With numerous efforts using reversedphase HPLC, centrifugal partition chromatography (CPC), silica-gel chromatography and gel filtration, the fatty acids could not be separated completely. The NMR and MS analyses of the partially purified sample suggested, by bioassay, that many of the antibacterial substances had aliphatic chains, carboxyl groups, and hydroxyl or keto groups. The compounds of interest had no potent UV absorption, 
which made their detection during the chromatographic procedure troublesome.

Therefore, we decided to convert the mixture of fatty acids to less polar derivatives that are easily purified on silica-gel and by HPLC. As carboxyl groups tend to give tailing peaks in various chromatographic techniques, the functional group was masked as diphenylmethyl ester. To mask the hydroxyl group, another polar functional group, the crude material was treated with 4-nitrobenzoyl chloride to give the corresponding 4-nitrobenzoate (Scheme 1). The derivatives were also expected to be easily detectable because of intense UV absorption of the newly introduced aromatic moieties.

In fact, fully protected derivatives of paleic acid (5) and (R)-16hydroxylinoleic acid (6) could be isolated in pure form after successive silica-gel column chromatography and HPLC. Each derivative was independently deprotected under alkaline conditions and subse-

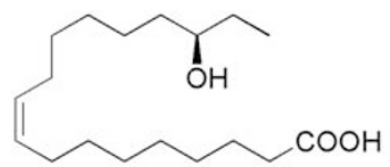

Paleic acid (1)

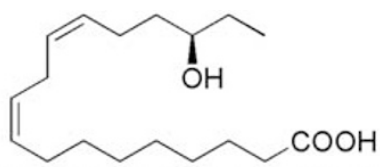

(R)-16-hydroxylinoleic acid (2)
Figure 1 Structure of paleic acid (1) and (R)-16-hydroxylinoleic acid (2).

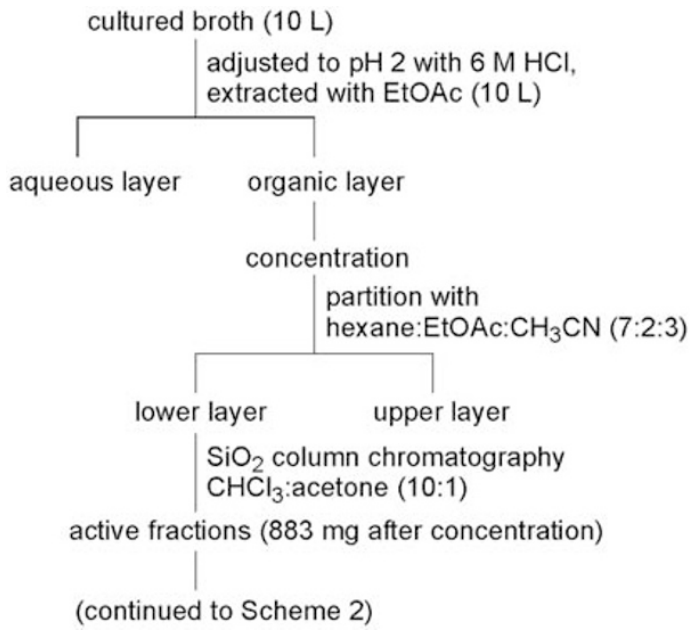

Scheme 1 Isolation of paleic acid (1) and (R)-16-hydroxylinoleic acid (2) quently purified with CPC to give paleic acid (1, 15 mg) and (R)-16-hydroxylinoleic acid $(2,15 \mathrm{mg})$.

Although many other fatty acids (judged by mass spectrum) were found in the bioactive fractions obtained by the first silica-gel column chromatography, these compounds except for $\mathbf{1}$ and $\mathbf{2}$ could not be separated as analytically pure samples. Further purification of the rest of the fatty acids is currently ongoing.

\section{Structure determination}

The physicochemical data of the paleic acid (1) are summarized in Table 1 . The compound was obtained as a colorless oil $\left([\alpha]_{\mathrm{D}}^{28}-5.00^{\circ}\right.$, c $\left.0.2, \mathrm{CHCl}_{3}\right)$, and its molecular formula was determined to be $\mathrm{C}_{18} \mathrm{H}_{34} \mathrm{O}_{3}$ by HRFABMS $\left((M-H)^{-}, m / z \quad 297.2426, \Delta 0.2 \mathrm{mDa}\right)$, revealing a degree of unsaturation of 2 . The compound displayed end absorption in its UV spectrum and a characteristic absorption at $1712 \mathrm{~cm}^{-1}$ in its IR spectrum.

As shown in Table 2, the ${ }^{1} \mathrm{H},{ }^{13} \mathrm{C}$, DEPT, HMQC, ${ }^{1} \mathrm{H}-{ }^{1} \mathrm{H}$ COSY, TOCSY and HMBC spectra of 1 suggested that the structure of the compound is an unsaturated linear fatty acid composed of 18 carbons, with one hydroxyl group at the C16 position and one olefin moiety (Figure 2).

The UV absorption data indicated that paleic acid has no aromatic moiety within its structure. The ${ }^{13} \mathrm{C}$ signal at 178.3 p.p.m., IR absorption signal at $1712 \mathrm{~cm}^{-1}$, and the result of treatment with trimethylsilyldiazomethane (a synthetic intermediate of the Mosher derivatives of paleic acid) strongly suggested that the compound contains a carboxyl group.

Compound 1 displayed the characteristic DEPT charts with 13 of 18 carbon signals corresponding to $\mathrm{CH}_{2}$. The other carbon signals correspond to one quaternary carbon of a $\mathrm{COOH}$ group, two $\mathrm{CH}$ and one $\mathrm{CH}_{3}$. Two protons correlated to one methine carbon peak (130.0p.p.m.) in the HMQC experiment, suggesting that the two carbon signals arising from the disubstituted olefin completely overlap.

Figure 2 summarizes the multidimensional NMR experiments of 1. The HMQC and HMBC experiments revealed that the $\mathrm{CH}_{3}$ was separated by one $\mathrm{CH}_{2}$ from the $\mathrm{CH}$ carbon at 73.5 p.p.m. The proton connected to the methine has a chemical shift of 3.54 p.p.m. On the basis of the molecular formula of $\mathbf{1}$, the substituent must be $\mathrm{OH}$.

Although the structure of $\mathbf{1}$ was determined as 16-hydroxyoctadecenoic acid, the position of double bond could not be defined. To this end, an EI-MS fragmentation analysis of the pyrrolidine amide derivative of 1 was conducted according to reported procedures. ${ }^{11}$ The

Table 1 Physicochemical data of paleic acid (1) and (R)-16-hydroxylinoleic acid (2)

\begin{tabular}{|c|c|c|}
\hline & Paleic acid (1) & (R)-16-hydroxylinoleic acid (2) \\
\hline Appearance & Colorless oil & Colorless oil \\
\hline Molecular formula & $\mathrm{C}_{18} \mathrm{H}_{34} \mathrm{O}_{3}$ & $\mathrm{C}_{18} \mathrm{H}_{32} \mathrm{O}_{3}$ \\
\hline \multicolumn{3}{|l|}{ HRFABMS (neg, m/z) } \\
\hline Found: & $297.2426(M-H)^{-}$ & $295.2270(M-H)^{-}$ \\
\hline Calcd: & $297.2424\left(\right.$ as $\mathrm{C}_{18} \mathrm{H}_{33} \mathrm{O}_{3}$ ) & $295.2268\left(\right.$ as $\mathrm{C}_{18} \mathrm{H}_{31} \mathrm{O}_{3}$ ) \\
\hline$[\alpha]$ & $-5.00^{\circ}\left(c 0.2, \mathrm{CHCl}_{3}\right)$ & $-0.48^{\circ}(c 0.14, \text { acetone })^{a}$ \\
\hline UV $\lambda_{\max }\left(\mathrm{CHCl}_{3}\right)$ & End absorption & End absorption \\
\hline $\mathrm{IR} v_{\max }(\mathrm{KBr}) \mathrm{cm}^{-\mathrm{a}}$ & $3448,2929,2854,1712,1629,1463,1409,1118,966,757$ & $3415,2929,2856,1712,1461,1411,1116,970,725$ \\
\hline TLC $\left(R_{\mathrm{F}} \text { value }\right)^{\mathrm{b}}$ & 0.42 & 0.42 \\
\hline Color reaction: positive & Molybdophosphoric acid-sulfuric acid & \\
\hline
\end{tabular}

${ }^{\mathrm{a}}[\alpha]_{\mathrm{D}}^{28}$ was recorded

bPlate: Silica gel $60 \mathrm{~F}_{254}$ (MERCK), $\mathrm{CHCl}_{3} / \mathrm{EtOH}=20: 1$. 
EIMS experiments of the pyrrolidine amide derivatives of the fatty acids showed characteristic series of fragments resulting from cleavage between each carbon-carbon single bond but not at a double bond. The observed mass numbers of the positive fragmentation ions containing the pyrrolidine moiety, when the methodology was applied to 1, is detailed in Supplementary information (See Supplementary Figure S1). As a result, only the fragment ions bisected between $\mathrm{C} 17$ and $\mathrm{C} 18$ and between $\mathrm{C} 9$ and $\mathrm{C} 10$ were not detected. Because a $\mathrm{C}=\mathrm{C}$ double bond at $\mathrm{C} 17 / \mathrm{C} 18$ was ruled out, on the basis of the extensive NMR study described above, the mass experiment clearly demonstrated that the olefin is located between the C9 and C10 positions. However, the geometry of the double bond could not be identified at this point because the chemical shifts of the two olefinic protons of 1 in the ${ }^{1} \mathrm{H}$ NMR spectrum were too close and the coupling constant between these protons could not be determined.

The absolute configuration of the secondary alcohol was unambiguously determined as $R$ by a modified Mosher method. Supplementary Figure S2 in Supplementary information summarizes the differences of the chemical shifts of $(S)$ - $\alpha$-methyl- $\alpha$-trifluoromethylphenylacetyl-paleic acid methyl ester and the $(R)-\alpha$-methyl- $\alpha$ trifluoromethylphenylacetyl-congener.

The peaks corresponding to $\mathrm{H} 9$ and $\mathrm{H} 10$ (5.32 and 5.35 p.p.m.) of the $(S)$ - $\alpha$-methyl- $\alpha$-trifluoromethylphenylacetyl ester were separated

Table $2{ }^{1} \mathrm{H}$ - and ${ }^{13} \mathrm{C}$-NMR data of paleic acid (1) and (R)-16-hydroxylinoleic acid (2)

\begin{tabular}{|c|c|c|c|c|c|c|}
\hline \multirow[b]{2}{*}{ Position } & \multicolumn{3}{|c|}{ Paleic acid (1) } & \multicolumn{3}{|c|}{ (R)-16-hydroxylinoleic acid (2) } \\
\hline & ${ }^{13} \mathrm{C}(\delta)$ & ${ }^{1} H(\delta)$ & $\begin{array}{c}\text { Multiplicity, } \\
J(H z)\end{array}$ & ${ }^{13} \mathrm{C}(\delta)$ & ${ }^{1} H(\delta)$ & $\begin{array}{c}\text { Multiplicity, } \\
J(H z)\end{array}$ \\
\hline 1 & 178.2 & & & 178.2 & & \\
\hline 2 & 33.9 & 2.34 & $\mathrm{t}, 7.4$ & 33.8 & 2.34 & $\mathrm{t}, 7.4$ \\
\hline 3 & 24.7 & 1.63 & m & 24.7 & 1.64 & $\mathrm{~m}$ \\
\hline 4 & $29.0^{a}$ & 1.31 & $\mathrm{~m}$ & $\mathrm{~b}$ & 1.34 & $\mathrm{~m}$ \\
\hline 5 & $29.1^{\mathrm{a}}$ & 1.31 & $\mathrm{~m}$ & $\mathrm{~b}$ & 1.34 & $\mathrm{~m}$ \\
\hline 6 & $29.1^{\mathrm{a}}$ & 1.31 & $\mathrm{~m}$ & b & 1.34 & $\mathrm{~m}$ \\
\hline 7 & $29.4^{a}$ & 1.31 & $\mathrm{~m}$ & $\mathrm{~b}$ & 1.34 & $\mathrm{~m}$ \\
\hline 8 & 27.1 & 1.98 & $\mathrm{~m}$ & 27.1 & 2.05 & $\mathrm{~m}$ \\
\hline 9 & 129.9 & 5.35 & $\mathrm{~m}$ & 130.2 & 5.38 & $\mathrm{~m}$ \\
\hline 10 & 129.9 & 5.35 & $\mathrm{~m}$ & 127.9 & 5.33 & $\mathrm{~m}$ \\
\hline 11 & 27.2 & 1.98 & $\mathrm{~m}$ & 25.6 & 2.80 & $\mathrm{~m}$ \\
\hline 12 & $29.6^{a}$ & 1.31 & $\mathrm{~m}$ & 128.7 & 5.38 & $\mathrm{~m}$ \\
\hline 13 & $29.8^{a}$ & 1.31 & $\mathrm{~m}$ & 129.5 & 5.39 & $\mathrm{~m}$ \\
\hline 14 & 25.5 & 1.44 & $\mathrm{~m}$ & 23.6 & 2.18 & $\mathrm{~m}$ \\
\hline 15 & 36.8 & 1.44 & $\mathrm{~m}$ & 36.6 & 1.52 & $\mathrm{~m}$ \\
\hline 16 & 73.5 & 3.54 & $\mathrm{~m}$ & 73.1 & 3.57 & $\mathrm{~m}$ \\
\hline 17 & 30.1 & $1.44,1.53$ & $\mathrm{~m}$ & 30.2 & 1.50 & $\mathrm{~m}$ \\
\hline 18 & 9.9 & 0.93 & $\mathrm{t}, 7.5$ & 9.9 & 0.94 & $\mathrm{t}, 7.5$ \\
\hline
\end{tabular}

aThese assignments are interchangeable.

bEither 28.9 or 29.4 (overlap). presumably because of the magnetic anisotropic effect of the benzene ring of the Mosher ester moiety. A ${ }^{1} \mathrm{H}$ NMR decoupling experiment of the $(S)$ - $\alpha$-methyl- $\alpha$-trifluoromethylphenylacetyl ester with irradiation at 1.31 and 1.98 p.p.m. (corresponding to $\mathrm{H} 7$ and12, and $\mathrm{H} 8$ and 11, respectively) clearly showed a coupling constant of $10.6 \mathrm{~Hz}$ between $\mathrm{H} 9$ and H10, which is a typical value for the $Z$ isomer. Eventually, the structure of 1 was unequivocally determined as $(9 Z, 16 R)$-16-hydroxy9-octadecenoic acid. The structure of 1 was also confirmed by chemical synthesis. ${ }^{12}$

The ${ }^{1} \mathrm{H}$ NMR spectra obtained from 2 are similar to those of $\mathbf{1}$. With molecular formula of $\mathrm{C}_{18} \mathrm{H}_{32} \mathrm{O}_{3}$, the structure of 2 was predicted to be a $\mathrm{C} 18$ fatty acid with two olefinic double bonds and one hydroxyl group. In fact, the ${ }^{13} \mathrm{C}$ NMR spectrum of 2 has four peaks corresponding to olefinic carbons $(\mathrm{CH}$ at 127.9, 128.7, 129.5 and 130.2 p.p.m. as confirmed by DEPT). As shown in Figure 2, the planar structure of 2 was determined to be 16-hydroxylinoleic acid by DEPT, HMQC and HMBC spectra. Extensive decoupling experiments with 6 clearly showed that each olefin adopts a $Z$ geometry. Finally, the modified Mosher method was used to determine the $R$ absolute configuration of the C16 center (Supplementary Figure S2). The two sets of two proton peaks adjacent to the olefins $(2.72 / 1.97$ and 2.72/2.15 p.p.m.) were irradiated to give simplified ${ }^{1} \mathrm{H}$ NMR spectra around the olefinic region. Both of the coupling constants between $\mathrm{H} 9$ and $\mathrm{H} 10$ and between $\mathrm{H} 12$ and $\mathrm{H} 13$ were $10.7 \mathrm{~Hz}$, which is typical of $Z$ olefin. Therefore, the structure of 2 was determined to be $(R)-16$ hydroxylinoleic acid.

\section{Biological activity}

The antibacterial activities of the isolated compounds were examined toward a panel of bacteria covering various strains of $M$. haemolytica and $P$. multocida, and representative pathogens of human disease. The results from these experiments are summarized in Table 3. Paleic acid

Table 3 Antibacterial activity of paleic acid (1) and (R)-16hydroxylinoleic acid (2)

\begin{tabular}{lccc}
\hline & \multicolumn{3}{c}{ MIC $\left(\mu g \mathrm{~m}^{-1}\right)$} \\
\cline { 2 - 4 } Test organisms & 1 & 2 & Tilmicosin \\
\hline M. haemolytica N791 & 0.78 & 12.5 & 1.56 \\
M. haemolytica N811 & 0.78 & 6.25 & 12.5 \\
M. haemolytica S801 & 1.56 & 12.5 & 3.13 \\
P. multocida No.6 & 12.5 & 50 & 3.13 \\
P. multocida Kobe & $>50$ & $>50$ & 3.13 \\
P. multocida TS-8 & 6.25 & 50 & 3.13 \\
P. multocida M-17 & $>50$ & $>50$ & 3.13 \\
H. somni 23N2359 & $>50$ & 50 & 6.25 \\
A. pleuroneumoniae NB001 & 6.25 & 12.5 & 6.25 \\
E. coli NIHJ & $>50$ & $>50$ & 25 \\
K. pneumoniae PCI 602 & $>50$ & $>50$ & 12.5 \\
\hline
\end{tabular}

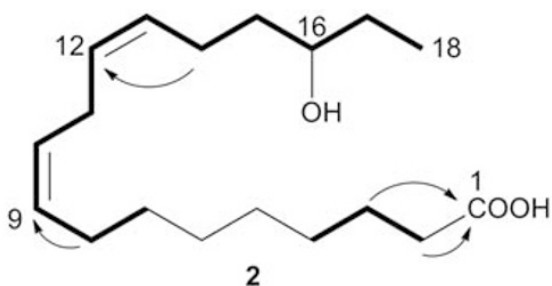

Figure 2 COSY (bold line) and selected HMBC correlation (arrows) of $\mathbf{1}$ and $\mathbf{2}$. 
(1) showed antibacterial activity toward several strains from $M$. haemolytica and $P$. multocida with MIC value ranging from 0.78 to $1.56 \mu \mathrm{g} \mathrm{ml}^{-1}$, and from 6.25 to $>50 \mu \mathrm{g} \mathrm{ml}^{-1}$, respectively. Notably, 1 displayed no activity against Echerichia coli and Klebsiella pneumoniae, suggesting that $\mathbf{1}$ is an antibiotic selectively effective against pathogens of bovine respiratory disease. On the other hand, 2 showed only moderate antibacterial activity against the tested organisms. In addition, 1 exhibited no activity toward representative strains of Staphylococcus aureus (Gram-positive bacteria).

A preliminary examination showed that $\mathbf{1}$ displayed practically no acute toxicity toward ICR mice by i.v. administration. Further studies, including in vivo tests and structure-activity relationships of synthetic analogs, are currently underway.

\section{EXPERIMENTAL PROCEDURE}

\section{General}

The purification steps before the treatment of diazodiphenylmethane were monitored with antimicrobial activity against $M$. haemolytica N811 using microbroth dilution method. The purification steps after the treatment of diazodiphenylmethane were monitored with analytical TLC using precoated $(0.25 \mathrm{~mm})$ silica-gel plates (Silica Gel $60 \mathrm{~F}_{254}$, cat. no. 1.05715 Kieselgel $60 \mathrm{~F}_{254}$, Merck KGaA, Darmstadt, Germany). Column chromatography was conducted with neutral silica-gel (Wakogel C-200, Wako Pure Chemical Industries, Osaka, Japan). Centrifugal liquid-liquid partition chromatography (CPC) was performed using a CPC240 system (Senshu Scientific, Tokyo, Japan). Optical rotations were obtained on a JASCO P1030 spectropolarimeter (JASCO, Hachioji, Japan) using a micro-cell (light path of $10 \mathrm{~cm}$ ). A Hitachi High-Tech U-2800 spectrophotometer (Hitachi, Tokyo, Japan) was used to record UV spectra, and IR spectra were measured using a Horiba FT-210 spectrometer (Horiba, Kyoto, Japan). NMR spectra were recorded using a JEOL JMN ECA $600(600 \mathrm{MHz})$ spectrometer (JEOL, Akishima, Japan). Chemical shifts $(\delta)$ are given in parts per million (p.p.m.), based on solvents as internal references, and coupling constants $(J)$ are presented in Hz. The abbreviations $\mathrm{t}$ and $\mathrm{m}$ indicate triplet and multiplet, respectively. HR-MS were taken under electron spray ionization conditions by a JEOL JMS-T100LC mass spectrometer (time of flight mass spectrometer) or a Thermo Fisher Scientific LTQ Orbitrap mass spectrometer (Thermo Fisher Scientific, Waltham, MA, USA). EI mass spectrum was recorded using JEOL JMS-SX102 mass spectrometer.

\section{Taxonomy}

Strain BMK771-AF3 was isolated from a soil sample collected at Kitaazumi-gun, Nagano, Japan, after the following protocol; the sample was treated by dry heating $\left(90^{\circ} \mathrm{C}, 1 \mathrm{~h}\right)$, suspended in sterile water, and spread onto glycerol-arginine-salt agar, ${ }^{13}$ which is supplemented with cycloheximide and nystatin as the selective inhibitors for fungi. The strain is Gram-positive, spore-forming and rod-shaped bacterium ( 0.7 to $0.8 \times 1.6$ to $2.5 \mu \mathrm{m})$. The cells of this strain are motile by means of peritrichous flagella. Central oval endospores $(0.45$ to $0.5 \times 1.0 \mu \mathrm{m})$ were observed in swollen sporangia. Colonies were colorless to light brownish gray, opaque and circular on nutrient agar. Growth occurred at $20-37^{\circ} \mathrm{C}$ (optimally at $30^{\circ} \mathrm{C}$ ). The DNA G+C content of strain BMK771-AF3 was 44.9 mol\%. The $16 \mathrm{~S}$ ribosomal RNA gene sequence (1483 bp, positions 24-1497, E. coli numbering system) of the strain showed high identity with members of genus Paenibacillus, ${ }^{14}$ such as P. taichungensis (BCRC 17757T EU179327, 1469/1475 bp, 99\%), P. pabuli (NRRL NRS-924T AB045094, 1473/1485 bp, 99\%) and P. xylanilyticus (XIL14T AY427832, 1475/ $1484 \mathrm{bp}, 98 \%$ ). These morphological characteristics and genetic analysis of the strain BMK771-AF3 suggested that the strain belongs to genus Paenibacillus. Therefore, the strain was designated as Paenibacillus sp. BMK771-AF3. Strain BMK771-AF3 has been deposited in the National Institute of Advanced Industrial Science and Technology, the International Patent Organism Depositary, Tsukuba, Japan, under the accession no. FERM P-16999.

\section{Fermentation}

A slant culture of the paleic acid-producing organism was inoculated into a 500-ml baffled Erlenmeyer flask containing $110 \mathrm{ml}$ of a seed medium consisting of $2.0 \%$ galactose, $2.0 \%$ dextrin, $1.0 \%$ Bacto Soytone (enzymatic digest of soybean meal, Becton, Dickinson and Company, Franklin Lakes, NJ, USA), 0.5\% corn steep liquor (byproduct of the corn wet-milling process, Oji Cornstarch, Tokyo,

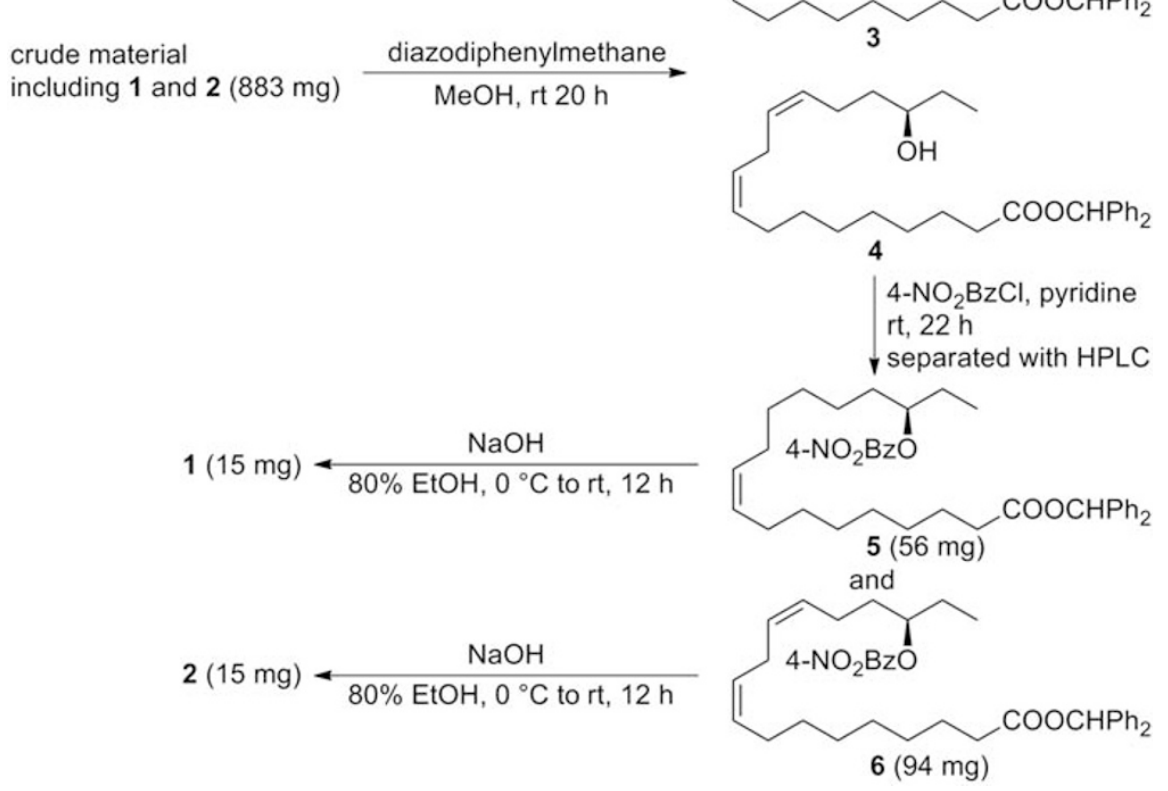

Scheme 2 Partial purification of paleic acid (1) and (R)-16-hydroxylinoleic acid (2). 
Japan), $0.1 \%\left(\mathrm{NH}_{4}\right)_{2} \mathrm{SO}_{4}$ and $0.2 \% \mathrm{CaCO}_{3}$ in deionized water ( $\mathrm{pH} 7.4$ before sterilization). The culture was incubated on a rotary shaker (180 r.p.m.) at $30^{\circ} \mathrm{C}$ for $18 \mathrm{~h}$. The seed culture $(2.5 \mathrm{ml})$ was transferred into a $500-\mathrm{ml}$ baffled Erlenmeyer flask containing $110 \mathrm{ml}$ of a producing medium consisting of $2.0 \%$ corn starch, $1.0 \%$ glucose, $0.5 \%$ corn steep liquor, $1.0 \%$ corn gluten meal (byproduct of the corn wet-milling process, Nihon Shokuhin Kako, Tokyo, Japan), $0.3 \% \mathrm{NaCl}, 0.25 \% \mathrm{NH}_{4} \mathrm{Cl}$ and $0.6 \% \mathrm{CaCO}_{3}$ in deionized water. The fermentation was carried out on a rotary shaker ( 180 r.p.m.) at $27^{\circ} \mathrm{C}$ for 3 days.

\section{Isolation and purification}

The fermentation broth (101, 91 flasks) was acidified with $6 \mathrm{M} \mathrm{HCl}$ (adjusted to $\mathrm{pH} 2$ ) and was extracted with 101 of EtOAc. After centrifugation of the resulting mixture, the organic layer was concentrated to dryness. The resulting residue was partitioned with a solvent system of hexane/EtOAc/ $\mathrm{CH}_{3} \mathrm{CN}$ $(7 / 2 / 3)$. The lower layer was concentrated and subjected to silica-gel column chromatography and then eluted with $\mathrm{CHCl}_{3}$ /acetone (10/1). The bioactive fractions were collected and evaporated to produce an oil $(883 \mathrm{mg})$ containing 1 and $\mathbf{2}$ (Scheme 2).

The crude material was dissolved in $50 \mathrm{ml} \mathrm{MeOH}$ and treated with diazodiphenylmethane $(860 \mathrm{mg}, 4.43 \mathrm{mmol})$. The reaction system was stirred at ambient temperature for $20 \mathrm{~h}$ and concentrated in vacuo. The residue was purified with silica-gel column chromatography $(200 \mathrm{~g})$ eluted with toluene/ EtOAc (30/1) to give diphenylmethyl esters of $\mathbf{1}$ and $\mathbf{2}$ (3 and $\mathbf{4}$, respectively). Evaporation of the solvents produced $423 \mathrm{mg}$ of crude products.

4-Nitrobenzoyl chloride $(500 \mathrm{mg}, 2.69 \mathrm{mmol}$ ) was added to the residue in $25 \mathrm{ml}$ of pyridine, and the resulting mixture was stirred at room temperature for $22 \mathrm{~h}$ under argon. After the reaction system was concentrated in vacuo, the residue was suspended in hexane/MeOH (6/1), and the insoluble material was filtered off. The filtrate was evaporated, purified successively with silica-gel $(20 \mathrm{~g})$ column chromatography (hexane/EtOAc $=20 / 1$ ) and HPLC (PEGASIL Silica (Senshu Scientific) $120-5,20 \times 250 \mathrm{~mm}$; hexane $/ \mathrm{EtOAc}=98 / 2$; flow rate $8 \mathrm{ml} \mathrm{min}^{-1}$ ) to give 4-nitrobenzoyl derivatives of paleic acid diphenylmethyl ester $(5,56 \mathrm{mg})$, and $(R)$-16-hydroxylinoleic acid diphenylmethyl ester $(6,94 \mathrm{mg})$.

Each sample was independently dissolved in a mixture of $4 \mathrm{ml}$ of EtOH and $0.5 \mathrm{ml}$ of $\mathrm{H}_{2} \mathrm{O}$, treated with $0.5 \mathrm{ml}$ of $1 \mathrm{M} \mathrm{NaOH}$ at $0{ }^{\circ} \mathrm{C}$, allowed to reach room temperature, and stirred for $12 \mathrm{~h}$. The solutions were acidified to $\mathrm{pH} 3$ by $1 \mathrm{M}$ $\mathrm{HCl}$, and then concentrated to dryness. The residues were purified with CPC (hexane/EtOAc/ $\mathrm{CH}_{3} \mathrm{CN}=5 / 1 / 4$, ascending mode) to yield paleic acid $(1,15 \mathrm{mg}$ ) and $(R)$-16-hydroxylinoleic acid (2,15 mg) (Scheme 1).

\section{Structure determination}

Extensive NMR experiments $\left({ }^{1} \mathrm{H},{ }^{13} \mathrm{C}, \mathrm{DEPT}\right.$, HMQC, ${ }^{1} \mathrm{H}-{ }^{1} \mathrm{H}$ COSY, TOCSY and $\mathrm{HMBC}$ ) were performed on $\mathbf{1}$ and $\mathbf{2}$ to determine the planner structure of these compounds (Figure 2). Other physicochemical data of 1 and 2 were collected and summarized in Table 1.

\section{Biological activity}

The MIC determinations were performed by the serial agar dilution method recommended by the Japan Society of Chemotherapy. ${ }^{15}$ Brain Heart Infusion agar (Difco, Becton, Dickinson and Company) was used for M. haemolytica and P. multocida, E. coli and K. pneumoniae, and Mueller-Hinton agar (Difco) supplemented with 5\% Fildes enrichment (BBL) was used for Actinobacillus pleuropneumoniae and Histophilus somni. The MIC values were observed after incubation for $17 \mathrm{~h}$ at $37^{\circ} \mathrm{C}$, for P. multocida and M. haemolytica, and after incubation in air-5\% $\mathrm{CO}_{2}$ at $37^{\circ} \mathrm{C}$ for $17 \mathrm{~h}$, for A. pleuropneumoniae and $H$. somni. The MIC values are listed in Table 3. Paleic acid (1) showed MIC values of 100, 100 and $>100 \mu \mathrm{g} \mathrm{ml}^{-1}$ against $S$. aureus FDA209P, Smith and MS9610, respectively.

\section{Acute toxicity}

To 4-week-old female ICR mice, 1 (2.0, 1.0, 0.5, 0.25 and $0.125 \mathrm{mg}$ per mouse, two mice were tested for each dosage) dissolved in 10\% $\mathrm{DMSO} / \mathrm{saline}$ (colorless, transparent) was injected i.v. Mortality of the mice was observed for 2 weeks. All the mice survived during the examination, which means $\mathrm{LD}_{50}$ of 1 is $>100 \mathrm{mg} \mathrm{kg}^{-1}$.

\section{ACKNOWLEDGEMENTS}

We thank Ms Yumiko Kubota and Ms Chisato Nosaka at the Institute of Microbial Chemistry, Tokyo, for collecting NMR data and toxicological experiments, respectively.

1 Rice, J. A., Carrasco-Medina, L., Hodgins, D. C. \& Shewen, P. E. Mannheimia haemolytica and bovine respiratory disease. Anim. Health Res. Rev. 8, 117-128 (2007).

2 Dabo, S. M., Taylor, J. D. \& Confer, A. W. Pasteurella multocida and bovine respiratory disease. Anim. Health Res. Rev. 8, 129-150 (2007).

3 Ose, E. E. \& Tonkinson, L. V. Single-dose treatment of neonatal calf pneumonia with the new macrolide antibiotic tilmicosin. Vet. Res. 123, 367-369 (1988).

4 Gorham, P. E. et al. Tilmicosin as a single injection treatment for respiratory disease of feedlot cattle. Can. Vet. J. 31, 826-829 (1990).

5 Yoshimura, H., Ishimaru, M., Endoh, Y. S. \& Kojima, A. Antimicrobial succeptibility of Pasteurella multocida isolated from cattle and pigs. J. Vet. Med. B Infect. Dis. Vet. Public Health 48, 555-560 (2001).

6 Norcia, L. J. L. et al. In vitro microbiological characterization of a novel azalide, two triamilides and an azalide ketal against bovine and porcine respiratory pathogens. J. Antibiotics 57, 280-288 (2004).

7 Evans, N. A. Tulathromycin: an overview of a new triamilide antimicrobial for livestock respiratory disease. Vet. Ther. 6, 83-95 (2005)and references cited therein.

8 Hendriksen, R.S. et al. Prevalence of antimicrobial resistance among bacterial pathogens isolated from cattle in different European countries: 2002-2004. Acta. Vet. Scand. 50, 28-37 (2008).

9 Lanser, A.C., Plattner, R. D. \& Bagby, M. O. Production of 15-, 16-, 17-hydroxy-9octadecenoic acids by bioconversion of oleic acid with Bacilluspumilius. J. Am. Oil Chem. Soc. 69, 363-366 (1992).

10 Brodowsky, I. D. \& Oliw, E. H. Metabolism of 18:2(n-6), 18:3(n-3), 20:4(n-6) and $20: 5(n-3)$ by the fungus Gaeumannomyces graminis: identification of metabolites formed by 8 -hydroxylation and by w2 and w3 oxydation. Biochim. Biophys. Acta. 1124, 59-65 (1992).

11 Andersson, B. A. \& Holman, R. T. Pyrrolidides for mass spectrometric determination of the position of the double bond in monounsaturated fatty acids. Lipids 9, 185-190 (1974).

12 Watanabe, T. et al. Synthesis of paleic acid, antimicrobial agent effective against Pasteurella and Mannheimia, and its structurally related derivatives. Paper in preparation.

13 El-Nakeeb, M. A. \& Lechevalier, H. A. Selective isolation of aerobic actinomycetes. Appl. Microbiol. 11, 75-77 (1963).

14 Ash, C., Priest, F. G. \& Collins, M. D. Molecular identification of rRNA group 3 bacilli (Ash, Farrow, Wallbanks and Collins) using a PCR probe test. Antonie. Van. Leeuwenhoek. 64, 253-260 (1993).

15 Japan Society of Chemotherapy. Method of MIC determination. Final report from the committee on antimicrobial susceptibility testing, Japanese Society of chemotherapy, on the agar dilution method. Chemother. 56, 49-57 (2008).

Supplementary Information accompanies the paper on The Journal of Antibiotics website (http://www.nature.com/ja) 